
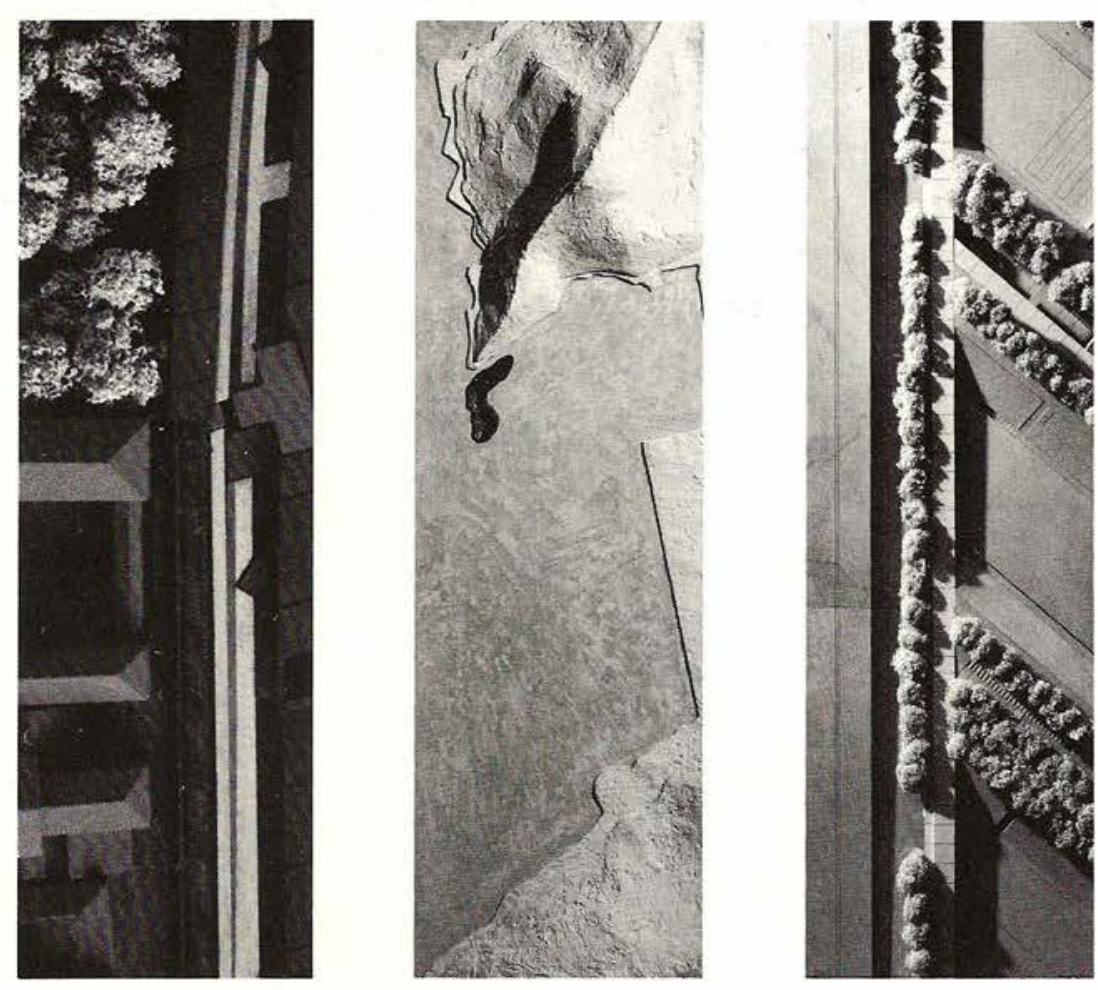

THREE PROJECTS

Renato Rizzi 


\section{Rediscovering the City}

\section{Zwischenwelt in Rovereto}

principal: R Rizzi

project team: F. Allocca, C. Bosio.
The city is in a process of moving away more and more from its quality of having 'place' because it is being rapidly homogenised. This has already happened in the peripheral areas and now there is a danger that the same contamination may happen even for the central areas.

In other words, it seems almost that the ways and customs that have progressively taken root in the suburbs are able to become models for imitation in designing the zones inside the city, forgetting that there exists an enormous bundle of generative grammars that have been produced from a slow process of modification and that these possess the features of an urban character.

\section{THE CHARACTER OF PLACE}

In terms of Rovereto the site represents a very important 'void', for all the city, a place in which figurative memory finds its expressive, oneiric forms, where the circus, the tournament, games, festivals: had their stage of illusion, a carnivalesque place. An indefinite place, however, that could fill up until it almost burst or remain empty, a void unutilised, transversed only by children's incursions. This place of thousands of limits and also of no limit, has a precious richness in defining the differential character of Rovereto. This space, a little protected, enclosed, this space of forgetting, has maintained its character of marginality even though surrounded by the contemporary city. An area with certain invisible aspects, free, that has never participated in and that has never been absorbed by urban re-organisation and has always resisted any transformational programme.

\section{THE HISTORIC ICONOGRAPHY}

A reading of historical images traces a process of modification principally by cancellations, by the loss of signs, by successive and continuing enfeebling to the point of their total disappearance. The constituent elements that structured the plan - small canals that incised the borders: the enclosing walls that are inscribed on the countryside - represented the continuation of an urban landscape much more articulate, much more complex than that deduced from the few remaining archaeological traces or indications

Some of them describe the entire development of a network of waterways, illustrating and recounting with an incredible precision and richness all the possible 
diversions, controls, closures, barriers, types of canals, locks, wheels dislocated along the entire tracing. The value of these maps is in being able to restore a tangled world of images, of sounds, noises, it allows us to see the entanglement of the timbers with the fine threads of silk in a deafening rotation of gears rotted by water, which wrap around each other setting the scene now for the great urban machine. Only in the book Invisible cities by Italo Calvino can one savour again this fascinating intricacy and from a different point of view, some sort of analogy is offered by the machines of Jean Tinguely. But one can interpret other things from these maps. It is the particular way of holding together the region, countryside, architecture even the particular internal constructs of the figure. Everything comes to be presented by their own image, all is expressible through the figures of a refined aesthetic logic.

\section{THE PLANNING PROGRAMME}

Above all the project is the endeavour to give a contemporary description of the city, it is the possibility of an urban narration through the figure. It expresses an undeniable aesthetic necessity if one wants the city to turn into a representation of itself grounding its own legitimacy on the necessity of use and not the contrary.

Therefore, the assumptions or themes of the figurative plan are:

a. the theme of the void: to construct the void as a distinct characteristic of the area;

b. the theme of transgression: to permit the possibility of welcoming again, the circus, the tournaments, the festivals, the games also fairs and markets at the limit;

c. the theme of inversion: to bind the area whether to the historic texture or to the modern orthogonal outlines, upsetting sense. While the more rigid contemporary plan imposed itself on the more delicate historical plan cancelling it out, now the historic generative grammars assume preeminence over the modern organising syntaxes.

d. the theme of the citation: the use of traces fragments, analogous figures, coming from the text of the city and from the iconographic memories, as referential citations

e. the theme of the theatrical: the insertion of the great natural landscape, the mountains inside the urban rim as a new and fascinating theme of the modern.

\section{THE FIGURATIVE PROGRAMME}

Two worlds, two landscapes look for their own space of confluence in the project. The first is an horizontal space, taut, even slightly concave, that almost covers 
completely the entire area. It is the space that represents the void, the place where anything can happen. It should resemble a piazza but it is not exactly that. It is a space liberated, open to everything and anybody, not institutionalised, whose one rule is that it no one possess it. Placed some metres above the level of the street it acts as roof - it could be more opportune to say, as shield - for the area below full of activity. It is a space that refers to the modern city, to its horizontal expansion.

The second represents a vertical space, deep, dense, from the forced and controlled views. The landscape of the border. It changes radically depending on the different ways one approaches it. If one travels along it in an east-west direction, following the development of the historical city, it becomes a true urban street of more levels, rich with objects and figurative surprises, supported by a building-wall that will also welcome residential use. It reflects a modern sloping of the street of the historical areas, since it places itself as an ideal continuity with it. The compactness of the fronts, the continual suspension, floating between a below and an above produces the analogy of serried and articulated perspectives.

If instead one comes from the north towards the south, the direction of the modern city, the edge is transformed into a soft organised margin of trees. A linear park of tall trees with the ground lower than the level of the streets becomes furrowed by the transversing pathways.

The figurative tension that it produces between the edge and the horizontal space makes a series of objects emerge, fragments that are none other than circulation spaces - stairs, ramps, entrances, bridges, gangways - between the two diverse systems. To establish a reverberation between the opposite edges they reflect the traces extracted from the pre-existing buildings in the area.

Standing in a central position one can, moreover, observe a hierarchy of horizons. The first is given by its own limits, the second those that appear at the edge higher than 2.4 metres - the third from the limits of the foliage of the trees, the fourth the urban skyline and last of all the scenography of the mountains. The point of view of the observer is no longer external to the city, but instead inside. It is no longer possible to perceive the city in its totality but only through parts, through traces and the texture of the fields in this case, no longer convex but concave since it is no longer nature but architecture.

The figure had to exceed its own confines (the physical confines of the area) to display its expressive charge derived from the confrontation with the different texts of the city. It had to search for a profound rootedness in memory and tradition knowing well that only thus could it possess the necessary strength to detach itself, to be able to reveal, to be transgressive and innovative. 
It has re-figured a middle space, a Zwischenwelt, an 'in-between world' which together hold the irre-soluble conflict between the historic city and the modern city, between the tight, fine, horizontal spaces, and the dense vertical spaces, between the limits that separate and the limits that include in a continual and incessant exchange of roles. The figure has thus finally unveiled the disquieting images of the place making them legible, liberating them from the prison of history. 